\title{
Malpractices of Milk Adulteration with Chemicals and Its Impact on Nutritional Status of Pre-school Children in Peshawar - Pakistan
}

\author{
Fahdullah Shakir ${ }^{1}$, Zia-ud Din ${ }^{1, *}$, Iftikhar Ahmad ${ }^{2}$, Imran Khan ${ }^{1}$, Muhammad Abbas $^{1}, Z_{\text {Zahoor Ahmad, }}{ }^{1}$ \\ Fazia Ghaffar ${ }^{3}$, Madiha Ilyas ${ }^{4}$, Saima Bibi ${ }^{5}$
}

\begin{abstract}
${ }^{1}$ Department of Human Nutrition, Faculty of Nutrition Sciences, University of Agriculture, Pakistan
${ }^{2}$ Department of Livestock Management, Breeding and Genetics, University of Agriculture, Pakistan

${ }^{3}$ Department of Food \& Nutrition, College of Home Economics, University of Peshawar, Pakistan

${ }^{4}$ Department of Food Science \& Technology, Government College Women University, Pakistan

${ }^{5}$ Department of Animal Nutrition, University of Agriculture, Pakistan
\end{abstract}

Copyright $\bigcirc 2017$ by authors, all rights reserved. Authors agree that this article remains permanently open access under the terms of the Creative Commons Attribution License 4.0 International License

\begin{abstract}
Milk is one of the most nutritious drinks. Chemical agents are frequently added in fresh cattle milk for different purposes including preservation, viscosity and flavor. A research study was conducted in District Peshawar -Pakistan to investigate contributing role of chemical adulterants in fresh milk on nutrition status of under five year children. Total of 203 households, having under 5 years children (free from any chronic disease) were randomly selected. Fresh milk samples were randomly collected from the households and tested for the presence of chemical adulterants. Children's nutritional statuses were assessed taking measurements on weight, height / length, and mid upper arm circumference (MUAC). Children nutritional statuses were assessed comparing their anthropometric measurements with WHO growth standards. Other relevant data i.e. child feeding history, fresh milk consumption by children, medical history, and socioeconomic status of children families were collected interviewing heads of households. Data were analyzed in SPSS software; multiple regression models were used to estimate association between milk adulteration and children nutrition status. Chemical adulterants including formaldehyde, boric acid, urea and hydrogen per oxide were found in total of 77 (38\%) milk samples. Children in the adulterated group (consumed adulterated milk $>6$ month) had significantly lower body weight, MAUAC and weight-for-age z-score (WAZ) comparing with those in the non-adulterated group $(p<0.05)$. Consumption of adulterated milk was among the risk factors for poor nutritional status identified through multivariate regression. It was concluded that consumption of adulterated milk contributed significantly to the poor nutritional statues of under 5 years children living in the study areas.
\end{abstract}

Keywords Chemical Adulterants, Fresh Milk, Children Nutrition Status, Pakistan

\section{Introduction}

Milk is universally considered as complete diet for children as it encompasses essential nutrients [1] that are highly bioavailable to the human body [2]. In addition to human milk, consumption of both goat and cow milk has been associated with the advancement in the physical growth of children [3]. Being the major source of calcium, milk and milk products are essential for a child to fulfill his average calcium requirement [4]. Review on infant and child nutrition showed that cow's milk is recommended to be introduced to children after certain age, e.g. before 12 months in UK [5] and USA [6], gradually from the age of 9 months in Canada [7] and Denmark [8] and from 10 months in Sweden [9]. Milk and milk formula play a major role as a source of energy in the infants' diet. Bottle-fed porridges prepared with cow's milk and various kinds of cereals are a common complementary food in developing countries [10].

Several adult rents are added to fresh cattle milk for various purposes: milk powder and starch are added to improve its viscosity; water is added to enhance its volume; to increase its shelf life, ice and certain chemicals like hydrogen per oxide, carbonates, urea, bicarbonates, antibiotics, formalin and detergents are supplemented. These chemicals are added for different purposes: detergents are added to milk to compensate for the reduction in the foaming nature of fresh milk, caused by the addition of water to it. In a similar manner, urea is used for whitening the milk. Boric acid is added to milk during processing as a milk preservative in order to prevent the growth of micro-organism in it [11]. 
Various reports on quality and adulteration in fresh milk in Pakistan have been published, indicating that chemical agents are frequently added in fresh milk for different purposes including preservation, viscosity and flavor [12 16]. For business purposes, these chemical agents are usually added by illiterate to low educated milkmen who are having no idea or knowledge about chemical toxicity due to over-dosage and their ill-effect on human health. No single study in Pakistan has been conducted to investigate role and contribution of chemical adulterants in milk on nutritional status of children. As milk is a major ingredient of various child foods including weaning and complimentary feeds, keeping in view the importance of this issue, current project was designed to fill the existing gap in research on contributing role of chemical adulterants in milk on nutrition status of children under five year.

\section{Materials and Methodology}

Current study was conducted in urban and rural areas of district Peshawar. The study was conducted between 2012 and 2013. Rural and urban areas in Peshawar were identified contacting the census office Peshawar. 203 families were randomly selected from rural and urban areas (101 from urban and 102 from rural area). Selection criteria included families purchasing milk from a milkman or local milk shop for the last 6 months or more and having a child (6 - 59 months), free from any congenital defect and chronic diseases. The children were included if he/she consumed fresh milk either directly or indirectly in diet.

\subsection{Detection Chemical Adulterants in Milk Samples}

Samples of fresh milk were collected from each selected family to test for chemical adulterants. Milk samples were collected in sterilized bottle with cap, and labeled with required information i.e. area, house number, type of milk (either buffalo/cow or sheep) and date of collection. Samples were transferred to the Diary Technology Center (DTC), Department of Livestock Management, Faculty of Animal Husbandry and Veterinary Science, The University of Agriculture, Peshawar, for further analysis. All essential hygienic precautions were followed to prevent contamination of milk.

Chemical adulterants including formalin, hydrogen peroxide, urea, and boric acid were determined using standardized AOAC (2000) procedures [17]. For formalin, one $\mathrm{ml}$ milk sample was taken in test tube. One $\mathrm{ml}$ regent (conc. sulphuric acid) was added along the sides of the test tube without shaking. Appearance of violet purple ring at the intersection of the two layers showed the presence of formalin while that of yellow ring at the junction showed its absence. For Hydrogen Peroxide, One $\mathrm{ml}$ regent (paraphenylenediamine) was added along the sides of the test tube containing one $\mathrm{ml} \mathrm{milk} \mathrm{sample.} \mathrm{Changes} \mathrm{in} \mathrm{color} \mathrm{of}$ milk to chocolate red confirmed the presence of hydrogen peroxide in milk sample. Urea is generally added in the preparation of synthetic milk to raise the SNF (Solid-not-Fat) value. To determine urea in fresh milk samples, one ml milk sample was taken in test tube. One $\mathrm{ml}$ regent (paradimethyl amino benzaldehyde) was added in the test tube. Presence of yellow color shows positive milk sample for urea, while no color detected negative milk sample. Boric acid was added to milk as preservatives. One $\mathrm{ml}$ of milk sample was taken in a test tube. One $\mathrm{ml}$ regent (conc. Hydrochloric acid) was added in test tube.

\subsection{Nutritional Status Assessment}

Nutritional statuses of the children were assessed taking their anthropometric measurements including weight, length/height and mid upper arm circumference (MUAC). These measurements were taken using standardized procedures and equipment's. Weight was taken in light dress using standardized uniscale for children. Length/height board was used for measuring children's length/height in centimeters after removing shoes and cap of the child. MUAC was measured using a non-stretchable measuring tap at mid-point between the acromion and olecranon processes. All anthropometric measurements of children were compared to WHO standards [18] to generate their respective z-scores. A child having $\mathrm{z}$-scores $<-2$ was identified as malnourished.

\subsection{Other Relevant Data}

Other relevant data were also collected thoroughly using standardized questionnaires. These included data on duration of fresh milk consumption by the children, dietary frequency per day, use of fresh milk in home-made child dishes families' socio-economic status, child medical history, and child's parent knowledge and awareness level regarding milk quality. Feeding history of toddlers and preschoolers were thoroughly investigated interviewing their mothers to get information about breastfeeding initiation, duration of breastfeeding and introduction of formula, complementary and solid feedings. Most of these variables were used as confounding factors for multivariate analyses.

\subsection{Statistical Analyses}

All data were entered into SPSS [19]. Different files for each set of data were generated to minimize data entry errors. All datasets were compound in SPSS to perform analysis. Descriptive statistics like frequency, mean, median and mode were used to see the data distribution and to check the data for errors. Children were categorized based on milk quality (consumption of chemically adulterated versus non-adulterated milk since last 6 months). Children in the 'adulterant group' were those consumed milk adulterated with chemicals since last 6 months or more while children in the other group were those consumed milk free of chemical adulterants. T-test was applied to find out the differences 
between the means of continuous variables of the groups. Multivariate regression analysis was performed to assess the independent effect of adulterated milk consumption on child's nutrition status. Values of $p<0.05$ were considered statistically significant.

\section{Result and Discussion}

Total of $38 \%(n=77)$ of the samples contained any of the tested chemicals (table 1). Milk samples were mostly collected during summer season, therefore this high chemical adulteration might be due to seasonal effect; however these findings indicate frequent and higher rate of misuse of chemicals as adulterants in the study area. Total of 77 families in the study areas (47\% rural; 53\% urban) were using adulterated milk since last 6 months or more suggesting that children from these families were constantly at the risk of getting health problems related to adulterated milk consumption.
Results on nutritional status indicators by the children' groups are shown in table -2 . No statistical differences were found between the groups for mean age, MUAC, length/height, Height-for-Age Z-score (HAZ), Weight-for-Height Z-score (WHZ) and MUAC-for -Age $Z$-score (MUACAZ); however means weight, MUAC and Weight- for-Age Z-score (WAZ) of the non-adulterated group were significantly higher than the rest $(p<0.05)$. These findings suggest that prolonged use of chemically adulterated milk might adversely affect current nutritional status. Weight is a good indicator of current nutritional status. Body weight reflects body composition and adipose tissue distribution in turn reflect a combination of genetic factors, physiological status, and dietary intake, individual's behavior and environmental and social influences. Food, among these influential factors, has a major impact on physiological status that is directly reflected by body weight. Associations between consumption of contaminated foods and poor nutritional status have been frequently reported previously [20-22].

Table 1. Quality of milk samples

\begin{tabular}{|c|c|c|c|}
\hline Adulterants & & \multirow{2}{*}{ No. of milk samples } & \multirow{2}{*}{ (\%) of milk samples } \\
\hline Chemicals adulterants & & & \\
\hline \multirow{2}{*}{ Formaldehyde } & Present & 19 & 9 \\
\hline & Absent & 184 & 91 \\
\hline \multirow{2}{*}{ Boric acid } & Present & 20 & 12 \\
\hline & Absent & 178 & 88 \\
\hline \multirow{2}{*}{ Hydrogen per oxide } & Present & 33 & 16 \\
\hline & Absent & 170 & 84 \\
\hline \multirow{2}{*}{ Urea } & Present & 05 & 2.5 \\
\hline & Absent & 198 & 97.5 \\
\hline \multirow{2}{*}{ Any chemicals* } & Present & 77 & 38 \\
\hline & Absent & 126 & 62 \\
\hline
\end{tabular}

*Presence of formaldehyde, boric acid, hydrogen peroxide or urea in milk samples.

Table 2. Nutritional indicators of the children

\begin{tabular}{|c|c|c|c|c|}
\hline \multirow{2}{*}{ Indicators } & \multirow{2}{*}{ Total children $(\mathrm{n}=203)$} & \multicolumn{2}{|c|}{ Adulteration with Chemicals } \\
\cline { 2 - 4 } & & \multirow{2}{*}{ No (n=126) } & \multirow{2}{*}{ Yes (n=77) } \\
\hline Child's age (months) & $28 \pm 10.9$ (Range: $8-59)$ & $29 \pm 11.1$ & $27.5 \pm 11.10$ & $\mathrm{~ns}$ \\
\hline Weight $(\mathrm{Kg})$ & $12.56 \pm 3.01$ & $12.88 \pm 2.63$ & $12.01 \pm 3.13$ & 0.042 \\
\hline MUAC $(\mathrm{Cm})$ & $14.19 \pm 1.87$ & $14.49 \pm 1.87$ & $13.67 \pm 1.82$ & 0.049 \\
\hline Height in $(\mathrm{Cm})$ & $85.18 \pm 12.71$ & $85.73 \pm 12.45$ & $84.88 \pm 13.14$ & $\mathrm{~ns}$ \\
\hline Weight-for-Age Z-score & $-0.47 \pm 1.50$ & $-0.29 \pm 1.39$ & $-0.76 \pm 1.63$ & 0.036 \\
\hline Height-for-Age Z-score & $-1.07 \pm 1.03$ & $-1.00 \pm 0.99$ & $-1.17 \pm 1.08$ & $\mathrm{~ns}$ \\
\hline Weight-for-Height Z-score & $-0.85 \pm 1.58$ & $-0.72 \pm 1.52$ & $-1.07 \pm 1.65$ & $\mathrm{~ns}$ \\
\hline MUAC-for-Age Z-score & $-0.82 \pm 1.70$ & $-0.74 \pm 1.79$ & $-0.94 \pm 1.54$ & $\mathrm{~ns}$ \\
\hline
\end{tabular}


Table 3. Multiple regression final models of predictors for WAZ

\begin{tabular}{|c|c|c|}
\hline Predictors & Regression Coefficients (SE) & $p$-value \\
\hline Child age (months) & $-1.75(0.69)$ & 0.039 \\
\hline Family size & $-0.71(0.59)$ & Ns \\
\hline Monthly income & $2.17(1.12)$ & 0.012 \\
\hline Mother awareness level & $0.32(0.66)$ & $\mathrm{ns}$ \\
\hline Father awareness level & $0.44(0.58)$ & 0.047 \\
\hline Deworming, Yes† $\dagger$ & $1.01(0.56)$ & Ns \\
\hline Child medical history*, Positive & $-0.58(0.77)$ & 0.50 \\
\hline Duration of breastfeeding (months) & $1.45(0.71)$ & $\mathrm{ns}$ \\
\hline Immunization, Yes & $0.77(0.61)$ & 0.034 \\
\hline Early initiation of complementary feeding, Yes** & $-1.23(0.70)$ & 0.021 \\
\hline Dietary intake (frequency per day) & $2.21(1.19)$ & 0.032 \\
\hline Milk quality, adulterated $\times$ & $-1.78(0.64)$ & \\
\hline
\end{tabular}

Child being dewormed in the last 6 month *parents reported that child had some medical problems in the recent past, for which they visited physician or hospital and the child used prescribed medicine ** Initiation of complementary feeding with continuation or cessation of breastfeeding before the age of 6 months $\times$ Milk quality based on presence of chemical adulterant and used by study child

As statistical differences in both weight and WAZ were evident between the groups; investigators decided to identify potential factors influencing child weight. Associations of various predictors (socio-demographic, feeding practices, dietary frequency, medical history, milk quality based on chemical adulterants) with children WAZ were further explored by regression models. Predictors associated with $\mathrm{WAZ}$ at $\mathrm{p}<0.20$ in univariate analysis were included and assessed in the multivariate model (table - 3). Predictors that were independently and positively associated with WAZ included family monthly income, child being dewormed in the last six months, duration of breastfeeding and dietary frequency per day. Adjusted negative associations of child age, early initiation of complementary feeding with continuation and / or cessation of breastfeeding before the age 6 months, and consumption of chemically adulterated milk were evident with child WAZ $(p<0.05)$. Our findings confirmed independent contribution of adulterated milk in poor nutritional status of the toddlers and preschoolers.

Milk is adulterated extensively in developing countries to the extent that greatly affects its nutritional value and makes it hazardous for consumers' health [23]. Chemical agents are frequently added in fresh milk for different purposes including preservation, viscosity and flavor. The adulterated food is unfit for human consumption particularly for children as it possibly consists of toxic substances. Milk adulteration can affect the health of the consumer in various ways. Urea can cause arrhythmia, pain in lower abdomen, muscle cramps, numbness and weakness in hands and feet, chilling fever, abnormal hair growth on face particularly on children and women and bleeding from uterus [24]. Formalin consumption in small amount may result in diarrhea, vomiting and abdominal pain while large quantity may cause hypothermia, shallow respiration, weak irregular pulse and unconscious. It also affects the optic nerve and may cause blindness [25]. Hydrogen peroxide injures the gastric cells causing gastritis and enteritis and bloody diarrhea [26]. Boric Acid can lead to diarrhea, nausea, vomiting, renal damage, acute failure of circulatory system and even death [27].

Our study has certain strengths and limitations. Though various studies have been conducted in Pakistan on the presence of chemical adulterants in milk, this was the first ever study conducted in Pakistan that investigated association of chemically adulterated milk use with child nutrition status adjusted for potential confounders. The sample size was pretty appropriate to represent the study area. WHO recommended techniques were used to assess nutritional status of the children. Z-scores for anthropometric measurements were generated using the WHO 2006 standards. Limitations may include the generalizability of the study findings to a larger population or to other parts of the country. Though, some studies conducted in other parts of the countries have also reported the presence of chemicals as adulterants in the milk [15, 20, 27, 28-30]; however none of these studies investigated its relationship with nutritional status of the consumers. Therefore, there is still need to explore the extent to which adulterated milk consumption contribute to the poor nutritional status of vulnerable groups in other parts of the country.

\section{Conclusions}

Malpractices of fresh milk adulteration with chemicals were found in the study area. Addition of unwanted chemical agents in fresh milk for different purposes was carried out usually by illiterate and unskilled persons who had no awareness of their toxic effect on human health. Chemically adulterated fresh milk was part of routine daily feeding of the toddlers and preschoolers. Children who consumed adulterated milk had significantly lower weight, MUAC and WAZ comparing to the rest. Study findings concluded that 
consumption of chemically adulterated milk was among the active factors contributing poor nutritional status of under 5 years children in the study area.

\section{Acknowledgements}

We are grateful to all children and their families who participated in the study.

\section{Conflict of Interests}

The authors declare that they have no competing interests.

\section{Funding}

The authors received no financial support for the research, authorship, and/or publication of this article.

\section{REFERENCES}

[1] Neville, MC. (1995). Determination of milk volume and composition. Hand book of milk composition. Editor Robert. G Jeusen. Academic press. pp. 87-97.

[2] Michaelsen, KF., Nielsen, AH., Roos, N., Friis, H. and Molgaard, C. (2011). Cow's milk in treatment of moderate and severe undernutrition in low-income countries. Nestlé Nutrition Institute Workshop series in Pediatric. 67: 102-107.

[3] Molgaard, C., Larnkjaer, A., Arnberg, K. and Michaelsen, KF. (2011). Milk and growth in children: effects of whey and casein. Nestlé Nutrition Institute Workshop series in Pediatric. 67: 67-68.

[4] Murphy, SP., Beaton, GH. and Calloway, DH. (1992). Estimated mineral intakes of toddlers Predicted prevalence of inadequacy in village populations in Egypt, Kenya, and Mexico. American Journal Clinical Nutrition. 56:565-572.

[5] Department of Health. (1994). Report on Health and Social Subjects No. 45.Weaning and the Weaning Diet. London, United Kingdom: HMSO.

[6] American Academy of Pediatrics, Committee on Nutrition. (1992). The use of whole cows' milk in infancy. Pediatrics. 89:1105-1109.

[7] Canadian Paediatric Society. (1998). Dieticians of Canada and Health Canada. Nutrition for Healthy Term Infants. Ottawa, Canada: Minister of Public Works and Government Services.

[8] The National Board of Health Denmark. (1998). Recommendations for the Nutrition of Infants; Recommendations for Health Personnel [in Danish].Copenhagen, Denmark: The National Board of Health (Denmark).

[9] Axelsson, I M., Gebre-Medhin., Hernell, OI., Jakobsonn, K.F. and Samuelson. G. (1999). Recommendations for prevention of iron deficiency. Delay cows' milk intake as a beverage to infants until 10-12 months of age. Läkartidningen. 96:22062208.

[10] Morais, TB. and Sigulem, DM. (2002). Determination of Macronutrients, by Chemical Analysis, of Home-Prepared Milk Feeding Bottles and their Contribution to the Energy and Protein Requirements of Infants from High and Low Socioeconomic Classes. The Journal of the American College of Nutrition. 21(3): 284-288

[11] Walker, GP., Dunshea, FR. and Doyle, PT. (2004). Effects of nutrition and management on the production and composition of milk fat and protein. Australian Journal of Agricultural Research. 55: 1009 - 1028 .

[12] Khan, M., Rajah, KK. and Haines, M. (1999). Quantitative techniques in the measurement of milk adulteration in Peshawar, Pakistan. International Journal of Dairy Technology. 52: $20-25$.

[13] Ayub, M., Quasid, A., Abass, M., Ihsan, MQ. and Iftikhar. AK. (2007). Composition and adulteration analysis of milk samples. Sarhad Journal of Agriculture. 23: 1127 - 1130.

[14] Javaid, SB., Gadahi, JA., Khaskeli, M., Bhutto, MB., Kumbher, S. and Panhwar, AH. (2009). Physical and chemical quality of market milk sold at Tandojam, Pakistan. Pakistan Veterinary Journal. 29(1): 27-31.

[15] Lateef, M., Faraz, A., Mustafa, MI., Akthar, P. and Bashir, MK. (2009). Detection of adulterants and chemical composition of milk supplied to canteens of various hospitals in Faisalabad city. Pakistan Journal of Zoology. 9: 139 - 142.

[16] Afzal, A., Mahmood, MS., Hussain, I. and Akhtar, M. (2011). Adulteration and microbiological quality of milk (a review). Pakistan Journal of Nutrition. 10 (12): 1195-1202.

[17] AOAC. (2000). Official methods of analysis of the Association of Official Analytical Chemists. Inc. Gaithersburg, U.S.A

[18] WHO (2006): The WHO Child Growth Standards. Available online on: http:/www.who.int/childgrowth/en/

[19] SPSS Inc. (2007). SPSS Base 16.0 for windows user's Guide Chicago IL.

[20] Faraz, A., Lateef, M., Mustafa, MI., Akhtar, P., Yaqoob, M. and Rehman, S. (2013). Detection of adulteration, chemical composition and hygienic Status of milk supplied to various Canteens of education Institutes and public places in Faisalabad. The Journal of Animal and Plant Sciences. 23(1): 119-124.

[21] Haasnoot, W., Smits., NG., Voncken, AEK. and Bremer, MG. (2002). Fast biosensor immunoassays for the detection of cows' milk in the milk of ewes and goats. Journal of Dairy Research.71:322-329.

[22] Li, Z., Wu, LL., Wang, YP., Liu, AM., Zou, CC. and Zhao, ZY. (2009). Melamine contaminated milk products induced urinary tract calculi in children. World Journal of Pediatrics. 5 (1):31-35.

[23] Loudon and Irvine. (1986). Deaths in childhoods from the eighteenth century to 1935.Medical History. 30: $1-41$.

[24] Baumgartner, M., Flock, M., Winter, P., Lu, W. and Baumgartner, W. (2005). Evaluation of flow injection 
analysis for determination of urea in sheep's and cow's milk. Acta Veterinaria Hungarica. 50: $263-271$.

[25] McGwin, G., Lienert, J. and Kennedy, JI. (2009). Formaldehyde exposure and asthma in children. A systematic review. Environmental Health Perspectives. 118: 313-317.

[26] [26] Wiles, MR., Williams, J. and Ahmad, KA. (2011). Essentials of dermatology for chiropractors. Jones and Bartlett Publishers, pp. 160-161.

[27] See, AS., Salleh, AB., Bakar, FA., Yusof, NA., Abdulamir, AS. and Heng, LY. (2010). Risk and health effect of boric acid. American Journal of Applied Sciences. 7: 620-627.
[28] Khan, BB., Mustafa, MI., Abdullah, M. and Yaqoob, M. (1991). Chemical and hygienic quality of milk supplied to canteens of various hospitals in Faisalabad city. Pakistan Journal of Agricultural Sciences. 28 (4): 404-407.

[29] Mustafa, MI., Khan, BB., Abdullah, M. and Khan, LA. (1991). Chemical and hygienic quality of milk supplied to canteens of various educational institutions in Faisalabad city. Pakistan Journal of Agricultural Sciences. 28 (1): 9-12.

[30] Barham, GS., Khaskheli, M., Soomro, AH. and Nizamani, ZA. (2014). Extent of extraneous water and detection of various adulterants in market milk at Mirpur khas, Pakistan Journal of Agriculture, Agricultural engineering and Veterinary sciences. 7(3): 83-89. 